\title{
Development and validation of stability indicating rp-uplc assay method for the determination of lacosamide and quetiapine fumarate in bulk and tablet dosage forms
}

\author{
Original \\ Article \\ Tene Sivaganesh $^{1,2}$, T.Siva Rao ${ }^{1 *}$, K.Ramasrinivas ${ }^{2}$, U.SeshamRaju ${ }^{2}$, \\ Y.M.Shasikiran', G. Raja ${ }^{2}$ \\ ${ }^{1}$ Department of Inorganic and Analytical Chemistry, Andhra University, Visakhapatnam, \\ Visakhapatnam District, 530003, India. \\ ${ }^{2}$ Department of Analytical chemistry, Aurobindo Pharma Ltd, Pydibhimavaram, Srikakulam \\ District, 532409, India.
}

\begin{abstract}
Validation of stability indicating RP-UPLC assay method for the determination of Lacosamide and Quetiapine fumarate in pharmaceutical products. This method has showed a high degree performance in separation and quantification of Lacosamide and Quetiapine even in the presence of its impurities. The separation was quite efficient on waters acquity BEH C18 column $(50 \mathrm{~mm} \times 2.1 \mathrm{~mm}, 1.7 \mu \mathrm{m})$ having used the phosphate buffer $\mathrm{pH} 2.5$ and acetonitrile in the ratio of $75: 25 \mathrm{v} / \mathrm{v}$ with a flow rate of $0.2 \mathrm{~mL} / \mathrm{min}$. The detection was carried out at $210 \mathrm{~nm}$ and the elution run time was $5.0 \mathrm{~min}$. The method was linear and found to be in the range between $0.0149 \mu \mathrm{g} / \mathrm{mL}-74.71 \mu \mathrm{g} / \mathrm{mL}\left(\mathrm{r}^{2}=0.9999\right)$ and $0.0148 \mu \mathrm{g} / \mathrm{mL}-74.67 \mu \mathrm{g} / \mathrm{mL}\left(\mathrm{r}^{2}=0.9999\right)$ for Lacosamide and Quetiapine respectively. The limit of detection $0.0149 \mu \mathrm{g} / \mathrm{mL}, 0.0148 \mu \mathrm{g} / \mathrm{mL}$ and quantification $0.031 \mu \mathrm{g} / \mathrm{mL}, 0.030 \mu \mathrm{g} / \mathrm{mL}$ for Lacosamide and Quetiapine were determined respectively. The precision result of the method ' $\%$ RSD' is less than $0.70 \%$ and the recovery \% of Lacosamide, Quetiapine is between 99.1 and 99.9. When the drug is subjected to different stress conditions, the consequential degradation products obtained could not interfere with Lacosamide and Quetiapine during the determination.
\end{abstract}

Received: 16 March 2019, Accepted: 18 July 2019

Key Words: Lacosamide; Quetiapine Fumarate; RP-UPLC; Stability indicating; Validation.

* Corresponding Author: Sivarao Tirukkovalluri, Department of Inorganic and Analytical Chemistry, Andhra University, Visakhapatnam, India, Post Office Box: 530003, Tel.: + 917702110459, E-mail: sivaraotvalluri.16@gmail.com.

Bulletin of Faculty of Pharmacy, Cairo University, ISSN: 1110-0931, Vol. $57 \quad$ No. 2

\section{INTRODUCTION}

Quetiapine fumarate (QUE), che mi cally known as 2-[2-(4-Dibenzo [b,f] $]^{[1,}$ 4] Thiazepin-11-YL-1Piperazinyl)Ethoxy] Ethanol, (E)-2-Butenedioate (2:1) (Salt) as shown in (Figure 1) is one of the dibenzothiazepine derivatives. It is used as an atypical antipsychotic drug and is prescribed for the treatment of schizophrenia and bipolar disorders ${ }^{[1-3]}$. QUE has no official Pharmacopoeia monograph of the analytical procedure for its assay in pure form as well as in dosage form. However, many analytical methods have been reported by different researchers for its determination in pure form, formulations and in biological materials. The highperformance liquid chromatographic methods ${ }^{[4-12]}$, UPLC with tandem MS detection ${ }^{[13,14]}$, chemiluminescence ${ }^{[15]}$, gas chromatographic ${ }^{[16,17]}$ and voltammetric ${ }^{[18]}$ techniques are used for assay of QUE in body fluids. Literature for capillary zone electrophoresis ${ }^{[19]}$, HPTLC ${ }^{[20-23]}$ and spectrophotometers ${ }^{[24-29]}$ is available for the determination of QUE in pharmaceuticals.

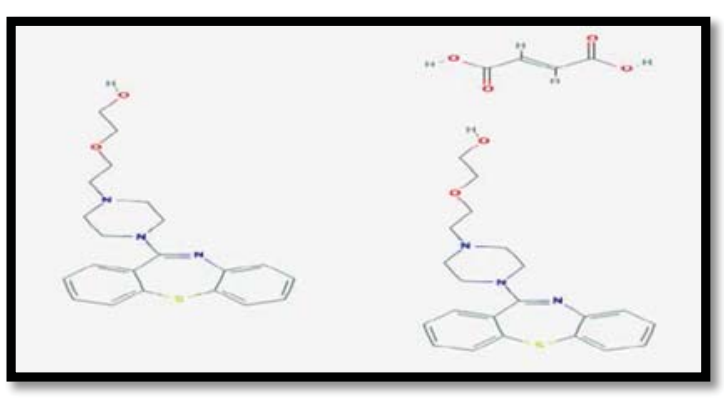

Figure 1: Chemical structure of Quetiapine Fumarate (QUE).

Lacosamide (LAC), as shown in the (Figure 2), is a newly licensed drug used in the treatment of diabetic neuropathic pain and partial onset seizures in adults with epilepsy. It is an amino acid functioning with a novel mechanism of action by excellent oral absorption and excreted mainly in the urine. There is negligible protein binding and minimum interaction with other antiepileptic 
Drugs. Epilepsy is a major neurological disorder affecting up to $2 \%$ of the population worldwide each year with more than 1, 00,000 new cases in US alone and a few considerable number in India are diagnosed. LAC drug was approved by the United States Food and Drug Administration (FDA) in the year 2007. The drug shows electrophysiological characters and modulates some voltage-gated sodium channels interacting with slow inactivated sodium channels and binding with collapse in response to mediator protein ${ }^{[30]}$. The literature survey reveals that there are HPLC (High performance liquid chromatography) Methods ${ }^{[31-37]}$ and UPLC methods ${ }^{[38,39]}$ available furthermore to the best of our knowledge; no stability-indicating UPLC method has been reported in the literature for these two compounds in a single method. Nowadays, UPLC ${ }^{[40-42]}$ is an innovative and the most preferred technique for analysis because of its decreased sample run times, lesser solvent and significantly improved productivity than HPLC. The replacement of standard $5 \mu \mathrm{m}$ particles in conventional HPLC column with sub $2 \mu \mathrm{m}$ particles in UPLC has resulted in significant improvements in resolution, sensitivity, speed, and minimized band spreading. The significance of this stability indicting UPLC method is from the above literature references. It reveals that there has been no single determination of stability-indicating UPLC analytical method reported so far for the assay of both QUE and LAC in pharmaceuticals. The advantage of this method was its single method determination for both antipsychotic (QUE) and antiepileptic (LAC) drugs.

Hence, an attempt was made to develop and validate a sensitive, accurate, precise and stability-indicating UPLC method for the determination of QUE and LAC in bulk and tablets dosage forms as per $\mathrm{ICH}^{[43]}$ guidelines.

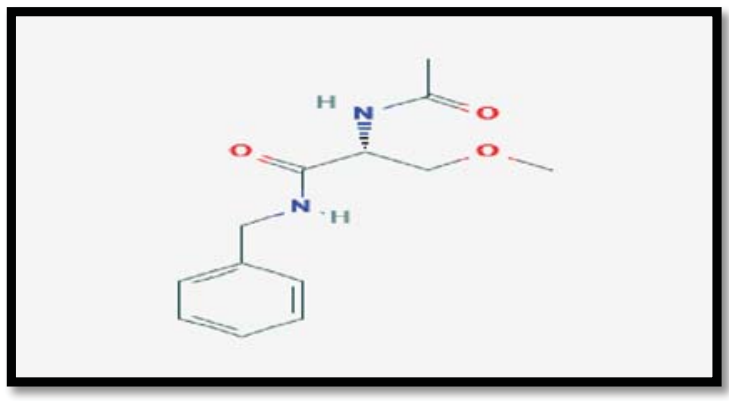

Figure 2: Chemical structure of Lacosamide (LAC).

\section{EXPERIMENTAL}

\section{Chemicals and reagents}

Samples of LAC, QUE were contributed by Aurobindo Pharma Ltd, Pydibhimavaram, India. HPLC grade Acetonitrile, AR grade $\mathrm{KH}_{2} \mathrm{PO}_{4}$ and Orthophosphoric Acids Were purchased from Merck India Ltd, Mumbai. HPLC water was prepared using a Millipore Milli-Q water purification system. It was also used to prepare all the solutions. Waters Acquity CSH Phenyl hexyl $(100 \times 2.1 \mathrm{~mm}, 1.7 \mu \mathrm{m})$ column (Part no. \# 186005407), waters Acquity BEH C18 column $(50 \mathrm{~mm} \times 2.1 \mathrm{~mm}, 1.7 \mu \mathrm{m})$ and waters acquity HSS T3column $(100 \mathrm{~mm} \times 2.1 \mathrm{~mm}, 1.8 \mu \mathrm{m})$ was procured from Waters India Ltd, Bangalore.

\section{Instrumentation (Apparatus)}

Acquity UPLC system equipped with an LC pump (model ACQ-BSM) used for method development and validation. It contains an online degasser, auto sampler (model ACQ-SM) with thermostat and detector (TUV) (model ACQ-TUV). The data was acquired, monitored and processed using the Empower3 software. Design expert version 9 (Stat-Ease Inc., Minneapolis, USA) was used for the optimizing chromatographic conditions. The buffers $\mathrm{pH}$ was monitored by using Metrohm $780 \mathrm{pH}$ meter and weights were taken using the Sartorius CPA225D balance. In this research work, we've attempted various chromatographic columns for method development. After a number of trails, we've selected Waters Acquity BEH C18 column $(50 \mathrm{~mm} \times 2.1 \mathrm{~mm}, 1.7 \mu \mathrm{m})$ based on its performance.

\section{Chromatographic conditions}

The chromatographic separations were Performed using waters acquity BEH C18 column

$(50 \mathrm{~mm} \times 2.1 \mathrm{~mm}, 1.7 \mu \mathrm{m})$. The buffer $\mathrm{KH}_{2} \mathrm{PO}_{4}$ was

Adjusted to $\mathrm{pH} 2.5$ by adding ortho phosphoric acid. The mobile phase contains a buffer ( $\mathrm{pH} 2.5)$ and acetonitrile in the ratio of $(75: 25 \mathrm{v} / \mathrm{v})$. The flow rate of the mobile phase is $0.2 \mathrm{~mL} / \mathrm{min}$. The column temperature was maintained at $50{ }^{\circ} \mathrm{C}$ and the absorption was measured at $210 \mathrm{~nm}$. The total run time of the method was $5.0 \mathrm{~min}$ and the injection volume, $1 \mu \mathrm{L}$. Water and Acetonitrile are taken in equal ratio as a diluent. Mobile phase and diluent solutions were filtered through $0.22 \mu$ finer porosity membrane filter. The eluting run time was completed within 5 minutes which is comparatively less than that of other HPLC methods for assay determination in the literature. Moreover, the injection volume of the sample required for the RP-UPLC method is $1 \mu \mathrm{L}$ which is sufficient. But in HPLC methods, it is needed about $20-40 \mu \mathrm{L}$. The retention time of LAC, QUE is $\sim 1.3$ and $\sim 3.0$ respectively.

\section{Preparation of solutions}

\section{Preparation of standard and sample solutions}

Accurately weighed and transferred $50 \mathrm{mg}$ each of LAC and QUE into a $100 \mathrm{~mL}$ clean dry volumetric flask, added $50 \mathrm{~mL}$ of diluent and sonicate to dissolve. Made up to volume with diluent and further diluted $5 \mathrm{~mL}$ of this solution to $50 \mathrm{~mL}$ with diluents and the overall concentration of $50 \mu \mathrm{g} / \mathrm{mL}$ for standard and sample solutions. 


\section{Calculation of LAC, QUE Assay}

The samples assay was calculated by the following equation:

$$
\frac{A T}{A S} \times \frac{W S}{100} \times \frac{5}{50} \times \frac{100}{W T} \times \frac{50}{5} \times P \times \frac{100}{(100-W . C)}
$$

Where AT is peak average area due to LAC in the sample preparation, AS is Average peak area due to LAC in the standard. WS is the weight of LAC standard taken in $\mathrm{mg}$, WT is the Weight of the sample taken in $\mathrm{mg}, \mathrm{P}$ is the Potency of the LAC working/reference standard. W.C is the water content (moisture content in sample) of the LAC. Same formula used for QUE.

\section{Results and Discussion}

\section{Method development and Optimization of RP-UPLC conditions}

The RP-UPLC conditions were optimized by using trials with different columns, several mobile phase compositions, flow rate and $\mathrm{pH}$. The analytical method development and validation play an important role in the determination of assay in pharmaceutical products. In this method, less quantity of solvents is used and the total consumption of solvents is $0.25 \mathrm{~mL}$ per runtime. One of the principles of green chemistry is prevention of waste. Further advantages of the RP-UPLC method are ability to increase the speed, sensitivity, and resolution compared to HPLC methods. By considering the above aspects, RP-UPLC instrument is the most suitable technique for the assay determination of LAC and QUE.

\section{Selection of stationary phase}

Stationary phase was selected based on the structures, pka values, molecular weight and impurities present in the products. A new waters acquity CSH phenyl hexyl column $(100 \mathrm{~mm} \times 2.1 \mathrm{~mm}, 1.7 \mu \mathrm{m})$ was initially screened for the separation but it failed to provide acceptable separation and peak shape. So, other stationary phases HSS T3 columns were screened for separation. And this had also failed to provide acceptable separation and peak shape. Then acquity BEH C18 column ( $50 \mathrm{~mm} \times 2.1 \mathrm{~mm}, 1.7 \mu \mathrm{m})$ was used and achieved a remarkable selectivity and hence it was finalized.

Waters Acquity BEH C18 column; The trifunctionally bonded $\mathrm{BEH}$ column particle gives the widest $\mathrm{pH}$ usage range i.e 1-12 range, superior low $\mathrm{pH}$ stability and ultralow column bleed for high sensitivity applications.

\section{Selection of Mobile phase}

As, one of the objectives of the method development is selection of buffers, potassium dihydrogen orthophosphate buffers were evaluated. It was observed that in potassium dihydrogen orthophosphate buffer is a promising candidate for efficient separation of impurities. To prepare the mobile phase two organic solvents were verified i.e methanol and acetonitrile at different composition conditions. Based on the compatibility with samples acetonitrile was finalized as an organic solvent.

\section{Selection of Diluent}

QUE: It is soluble to sparingly soluble in $0.1 \mathrm{~N}$ hydrochloric acid and slightly soluble in methanol, alcohol and water. But it's completely soluble in acetonitrile+ water composition besides being stable for at least 24 hours at $25{ }^{\circ} \mathrm{C}$. Hence, acetonitrile + water composition $(50: 50 \mathrm{v} / \mathrm{v})$ was selected as a diluent.

LAC: It is freely soluble in methanol, sparingly soluble in water and slightly soluble in ethanol. But it's completely soluble in acetonitrile + water composition and stable for at least 24 hours at $25{ }^{\circ} \mathrm{C}$. Hence, acetonitrile + water composition $(50: 50 \mathrm{v} / \mathrm{v})$ was selected as a diluent.

\section{Experimental design for optimizing flow rate, buffer concentration, and column temperature}

In initial method development trials with one factor at a time (OFAT) it was learnt that the flow rate, column temperature and composition of organic modifier had a significant impact on selectivity. Since optimizing the chromatographic parameters with OFAT approach consumes a lot of time and does not provide any design space, a design of experiments (DoE) was used for optimizing these chromatographic parameters. Based on the analysis, it was understood that to obtain good analyte peaks shape, column temperature and flow rate are to be monitored at $50{ }^{\circ} \mathrm{C}$ and $0.2 \mathrm{~mL} / \mathrm{min}$ respectively.

\section{Method Validation}

The developed analytical method was subjected to validation with respect to various parameters such as linearity, limit of quantification (LOQ), limit of detection (LOD), accuracy, precision, recovery studies, specificity and reproducibility as per the ICH guidelines.

\section{Specificity}

The specificity of the proposed method was demonstrated by the interference study. It was found that the presence of some common excipients wouldn't interfere at the retention time of LAC and QUE. Thus the developed method can be successfully applied for the determination of LAC and QUE in bulk drug and tablet dosage form.

\section{Blank and Impurities interference}

The blank, sample enriched with impurities were prepared and injected in RP-UPLC; no interference was observed at any of the peaks of interested in the blank.

The chromatogram given below at Figure 3 depicts the separation of all impurities. 


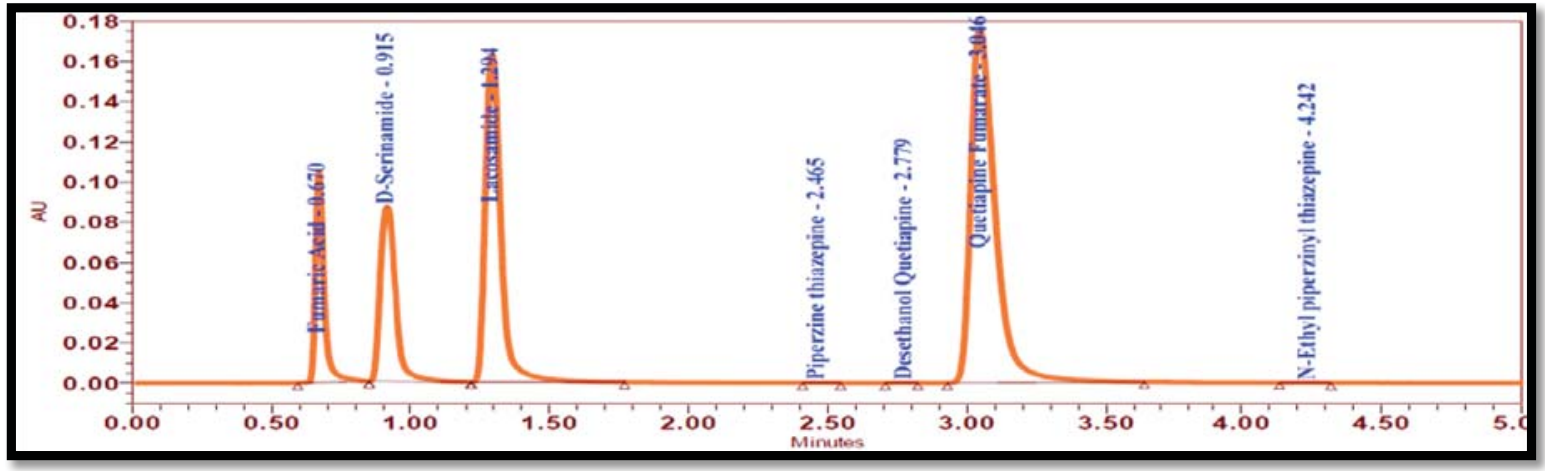

Figure 3: Impurity mixture of QUE and LAC.

\section{Forced degradation/Stress study}

In order to determine whether the analytical method and assay were stability-indicating, LAC and QUE bulk drug was stressed under various conditions to conduct forced degradation studies. All solutions were prepared to yield the concentration at $50 \mu \mathrm{g} / \mathrm{mL}$ for LAC and QUE.

\section{Acid degradation (5 $\mathrm{M} \mathrm{HCl} / 85^{\circ} \mathrm{C} / 2$ hours)}

The solution of LAC and QUE $(50 \mu \mathrm{g} / \mathrm{mL})$ for acid degradation study was prepared using $5 \mathrm{M}$ hydrochloric acid solution. Settled the resultant solution for two hours to allow acid degradation.

\section{Alkali degradation (5 $\mathrm{M} \mathrm{NaoH} / 85^{\circ} \mathrm{C} / 2$ hours)}

The solution of LAC\& QUE $(50 \mu \mathrm{g} / \mathrm{mL})$ for base degradation study was prepared using $5 \mathrm{M} \mathrm{NaOH}$. Allowed the resultant solution settle for two hours to ensure the alkali degradation.

\section{Oxidation (30 \% $\left.\mathrm{H}_{2} \mathrm{O}_{2} / 85^{\circ} \mathrm{C} / 10 \mathrm{~min}\right)$}

The solution of LAC and QUE $(50 \mu \mathrm{g} / \mathrm{mL})$ for peroxide degradation study was prepared using $30 \% \mathrm{H}_{2} \mathrm{O}_{2}$ Allowed resultant solution settle for $10 \mathrm{~min}$ to facilitate peroxide degradation.

\section{Thermal degradation $\left(105^{\circ} \mathrm{C} / 120\right.$ hours)}

LAC and QUE bulk drug was kept in the hot oven for 120 hours at $105^{\circ} \mathrm{C}$ to determine the effects of thermal degradation on the stability of samples.

\section{Photo stability}

LAC and QUE bulk drug was exposed to sunlight to determine the effects of light irradiation on the stability of samples in the solid state. Approximately $200 \mathrm{mg}$ of each LAC and QUE bulk drug was spread on a glass dish in a layer that was less than $2 \mathrm{~mm}$ thick. All samples for photo stability testing were exposed to indirect sunlight for 48 hours. Accurately weighed and transferred samples into volumetric flask to make the final concentration $50 \mu \mathrm{g} / \mathrm{mL}$. The proposed method evaluates the ability to separate the impurities of samples from its degradation products. The results are summarized in Table1.

Table 1: Degradation ${ }^{[43]}$ study results:

$\begin{array}{cc}\text { S. No. } & \text { Degradation } \\ 1 & \text { Acid Degradation } \\ 2 & \text { Base Degrdation } \\ 3 & \text { Peroxide Degradation } \\ 4 & \text { Thermal Degradation } \\ 5 & \text { Photolytic Degradation } \\ 6 & \text { Humidity Degradation }\end{array}$

$\%$ of Degradation

Condition

Quetiapine Lacosamide

UPLC

$\begin{array}{ccc}5 \mathrm{M} \mathrm{HCl} / 85^{\circ} \mathrm{C} / 2 \text { hours } & \text { Nil } & \text { Nil } \\ 5 \mathrm{M} \mathrm{NaoH} / 85^{\circ} \mathrm{C} / 2 \text { hours } & \text { Nil } & 0.4 \\ 30 \% \mathrm{H}_{2} \mathrm{O}_{2} / 85^{\circ} \mathrm{C} / 10 \text { min } & 14 & 0.3 \\ 105^{\circ} \mathrm{C} / 120 \text { Hours } & \text { Nil } & 0.1 \\ 1.2 \text { million Lux Hours } & \text { Nil } & 0.1 \\ 92.5 \% \mathrm{RH} / 25^{\circ} \mathrm{C} / 120 \text { Hours } & \text { Nil } & 0.2\end{array}$

Inference: The results from table 1 above are evidential that peroxide and base degradation process gives degradation products. The degradation related chromatograms are existing in supplementary data. 


\section{Linearity}

\section{Linearity for $L A C$ and $Q U E$}

The calibration curve was plotted over the concentration range of 0.0149 to $74.71 \mu \mathrm{g} / \mathrm{mL}$ of LAC and calibration curve was plotted over the concentration range of 0.0148 to $74.67 \mu \mathrm{g} / \mathrm{mL}$ of QUE. The calibration curves were prepared by plotting the peak area or response versus the concentration and analyzed through linear regression. The linearity was observed in the expected concentration range, demonstrating its suitability for analysis. The results are summarised in (Table 2).

Table 2: Performance of the proposed analytical method:

\begin{tabular}{lll}
\hline \multicolumn{1}{c}{ Parameter } & \multicolumn{1}{c}{ LAC } & \multicolumn{1}{c}{ QUE } \\
\hline Linearity range $(\mu \mathrm{g} / \mathrm{mL})$ & $0.0149-74.71$ & $0.0148-74.67$ \\
Wavelength $(\mathrm{nm})$ & 210 & 210 \\
Intercept & 1043.3616 & 553.2956239 \\
Slope & 12754.27091 & 21320.38572 \\
SD & 341619.3034 & 570570.6068 \\
Average & 291141.1667 & 485141.5 \\
Correlation coefficient & 0.9999 & 0.9999 \\
\% RSD & 117.338 & 117.6 \\
LOD ( $\mu \mathrm{g} / \mathrm{mL})$ & 0.0149 & 0.0148 \\
LOQ ( $\mu \mathrm{g} / \mathrm{mL})$ & 0.031 & 0.030 \\
Method Precision \%RSD & 0.35 & 0.35 \\
Intermediate precision \%RSD & 0.42 & 0.48 \\
Cumulative Precision \%RSD & 0.63 & 0.59 \\
\hline
\end{tabular}

LOD; Limit of detection RSD; Relative standard deviation

LOQ; Limit of Quantification SD; Standard deviation

nm; Nanometer

$\boldsymbol{\mu g}$; Microgram

Inference from table 2: Correlation coefficient values are within the acceptance criteria.

\section{Limit of Detection and Limit of Quantification}

The limit of detection (LOD) and limit of quantification (LOQ) were established for LAC and QUE by diluting the standard stock solution. The LOD concentration of LAC and QUE is $0.0149,0.0148 \mu \mathrm{g} / \mathrm{mL}$ respectively and on the other hand the LOQ concentration of LAC and QUE is $0.031,0.030 \mu \mathrm{g} / \mathrm{mL}$ respectively. The signal to noise ratio of LOD is '7, 7' for LAC and QUE respectively and the signal to noise ratio of LOQ is ' 13,11 ' for LAC and QUE respectively. Hence these were finalized as LOD and LOQ concentrations. Further precision was found to be $6.27 \%, 8.57 \%$ at LOD level $2.47 \%, 3.39 \%$ at LOQ level for analytes.

\section{Accuracy}

\section{The accuracy of $L A C, Q U E$}

The accuracy of the method was determined by calculating recoveries of LAC and QUE by the standard addition method. Known amounts of standard solutions of LAC and QUE (80, 100, and $120 \%$ level) were added to previously analyzed sample solutions of bulk drug. The
Percentage of recoveries was between 98.0 and 102.0. The results are summarized in the following (Table 3 ).

\section{Precision}

The precision of the method was demonstrated by system precision and method precision.

\section{System precision}

System precision for the as say was demonstrated by injecting standard solution under the same operating conditions. The peak areas of LAC and QUE were measured and the $\%$ RSD was found to be within acceptance criteria.

Inference: $\%$ RSD of the standard was found to be within the acceptance criteria i.e. NMT $1.0 \%$

\section{Method precision}

Method precision for analyte was demonstrated by preparing six samples at specification level. These solutions were injected along with a standard solution of LAC and QUE prepared at specification level. The relative standard deviation of all six preparations results were found to be $0.35 \%$.

Inference: \% RSD of results precision was found to be within the acceptance criteria i.e. NMT $1.0 \%$

\section{Intermediate precision (ruggedness)}

Intermediate precision for analyte was demonstrated by preparing six different samples at spec level by different analyst and different day. These solutions were injected along with a standard solution of LAC and QUE prepared at specification level. The relative standard deviation of analyte content obtained from all six preparations results were found to be $0.48 \%$.

Inference: The cumulative RSD's were found to be within the limit i.e. NMT1.0\%.

\section{Filter Compatibility}

Standard was injected without and with filter through Millipore Millex-HV (Hydrophilic PVDF $0.45 \mu \mathrm{m}$ ). QUE content was absorbed with the filter.

Inference: Filter compatibility to the sample is concluded from the study of the filter through Millipore Millex-HV (Hydrophilic PVDF $0.45 \mu \mathrm{m}$ ) indicated that there was absorption of QUE component to filter. So filtering was not recommended to this method through Millipore Millex-HV (Hydrophilic PVDF $0.45 \mu \mathrm{m}$ ).

\section{Solution Stability}

The standard and samples solutions were kept at room temperature of $25^{\circ} \mathrm{C}$ and injected the aged samples (Every one hour) into the RP-UPLC. The peak areas corresponding to LAC and QUE were measured. Calculated the similarity factor and found that the values are below $1.0 \% \mathrm{RSD}$. This indicates that the sample and standard solutions are most stable for at least 15 hours when stored at room temperature. Hence room temperature is considered for storage. 
Sivaganesh et al.

Table 3: Accuracy results:

\begin{tabular}{|c|c|c|c|c|c|c|}
\hline \multirow{3}{*}{ Parameters } & \multicolumn{2}{|c|}{ LAC } & \multicolumn{2}{|c|}{ QUE } & \multirow{3}{*}{\multicolumn{2}{|c|}{ Limit }} \\
\hline & \multirow[t]{2}{*}{ Initial SST } & \multirow[t]{2}{*}{ Bracketing SST } & \multirow[t]{2}{*}{ Initial SST } & \multirow{2}{*}{$\begin{array}{c}\text { Bracketing } \\
\text { SST }\end{array}$} & & \\
\hline & & & & & & \\
\hline Tailing factor & 1.38 & 1.38 & 1.60 & 1.60 & \multicolumn{2}{|c|}{ NMT 2.0} \\
\hline USP Plate count & 2864 & 2850 & 6203 & 6179 & \multicolumn{2}{|c|}{ NLT 2000} \\
\hline Retention time (min) & 1.29 & 1.29 & 3.05 & 3.06 & \multicolumn{2}{|c|}{$\begin{array}{c}\text { NLT } 2000 \\
\sim 1.30 \text { and } \sim 3.0\end{array}$} \\
\hline Resolution between & \multirow[t]{2}{*}{13.78} & \multirow[t]{2}{*}{13.51} & \multirow[t]{2}{*}{13.79} & \multirow[t]{2}{*}{13.81} & \multicolumn{2}{|c|}{ NLT 5.0} \\
\hline \multicolumn{3}{|l|}{ LAC, QUE } & & & & \\
\hline \multicolumn{7}{|c|}{ Precision } \\
\hline S.No. & \multicolumn{2}{|c|}{ LAC } & \multicolumn{2}{|c|}{ QUE } & \multicolumn{2}{|c|}{ Limit } \\
\hline Injection-01 & \multicolumn{2}{|c|}{638594} & \multicolumn{2}{|c|}{1070984} & & \\
\hline Injection-02 & \multicolumn{2}{|c|}{643217} & \multicolumn{2}{|c|}{1065564} & & \\
\hline Injection-03 & \multicolumn{2}{|c|}{642664} & & 943 & & \\
\hline Injection-04 & & 42444 & & 472 & $\underset{\sigma}{\pi}$ & \\
\hline Injection-05 & & 39281 & & 745 & 3 & \\
\hline Injection-06 & & 42986 & & 167 & : & \\
\hline Injection-07 & & 10716 & & 398 & & \\
\hline Mean & & 1415 & & 398 & & \\
\hline SD & & 1886 & & & & \\
\hline RSD & & 0.29 & & & & \\
\hline Trails & & $\mathrm{LAC}$ & & $\mathrm{JE}$ & & \\
\hline Accuracy & $\begin{array}{l}\text { A m o u } n \text { t } \\
\text { Added }(W / W)\end{array}$ & $\begin{array}{c}A \text { m o u } \quad \text { t } \\
\text { Rec ove r e d } \\
(W / W)\end{array}$ & $\begin{array}{c}\% \text { Recovery } \\
\text { (Criteria } 98.0 \\
\text { to } 102.0)\end{array}$ & 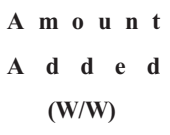 & $\begin{array}{c}\text { A m o u n t } \\
\text { Recover e d } \\
(W / W)\end{array}$ & $\begin{array}{c}\text { \% Recovery } \\
\text { (Criteria } 98.0 \\
\text { to 102.0) }\end{array}$ \\
\hline $80 \%$ Prep- 01 & 80.6 & 80.0 & 99.3 & 80.7 & 80.2 & 99.3 \\
\hline $80 \%$ Prep- 02 & 80.6 & 80.0 & 99.3 & 80.6 & 80.0 & 99.3 \\
\hline $80 \%$ Prep- 03 & 80.5 & 80.0 & 99.4 & 80.6 & 80.0 & 99.2 \\
\hline $100 \%$ Prep- 01 & 100.7 & 100.6 & 99.8 & 101.1 & 100.7 & 99.6 \\
\hline $100 \%$ Prep- 02 & 100.7 & 100.6 & 99.9 & 100.0 & 100.5 & 99.5 \\
\hline $100 \%$ Prep- 03 & 100.9 & 100.7 & 99.9 & 101.1 & 100.8 & 99.7 \\
\hline $120 \%$ Prep-01 & 118.5 & 118.0 & 99.6 & 121.2 & 120.5 & 99.4 \\
\hline $120 \%$ Prep- 02 & 119.2 & 118.8 & 99.7 & 121.1 & 120.4 & 99.5 \\
\hline $120 \%$ Prep- 03 & 120.7 & 119.6 & 99.1 & 121.2 & 120.3 & 99.3 \\
\hline
\end{tabular}

Inference: The result in the above table illustrates the recovered concentration of spiked samples being within the Acceptance criteria i.e. 98.0 to 102.0. 


\section{Tablet Analysis}

Twenty LAC tablets of Torrent Pharmaceuticals Company were purchased and analyzed with an equal quantity of 3 samples. Each $135 \mathrm{mg}$ tablet contains about 50mgsample of API. 20 tablets were taken and crushed with the help of mortar and then analyzed it in optimum chromatographic conditions. The average results of three tablets are within the specification limit and also 3 results of RSD are below $1 \%$.

\section{Details of Tablet:}

\section{Marketed By:}

Torrent pharmaceuticals limited, Indrad-382721, Dist Mehsana, India, B. No: RF0418001.

\section{Application to Pharmaceutical Industry}

This work will help the industry to develop, manufacture and launch the product in a fast and economical way which in turn reduces the cost of the medicine and help the patient to avail quality, innovative and affordable medicine.

\section{CONCLUSION}

A stability indicating RP-UPLC Assay method has been developed for the determination of LAC\& QUE. The developed method was proved to be robust using the experimental design. This method can be successfully implemented in the quality control lab for the routine analysis of this product. Further, this RP-UPLC method was successfully validated as per ICHQ2 (R1) guideline and proved to be precise, linear, sensitive, accurate, and robust. This method is short and simple, hence the implementation of this method in quality control and analytical development labs can yield high throughput. As low amounts of solvents are required, implementation of this method will be ecofriendly. This is the first RP-UPLC Assay method for the accurate quantification of the LAC\& QUE Assay in drug substance and drug product.

\section{Note:}

All other related figures and tables are provided in the supplementary part.

\section{ACKNOWLEDGES}

The authors are heartily thankful to acknowledge Aurobindo Pharma Ltd and Andhra University for providing all the facilities to carry out the research work.

\section{CONFLICT OF INTEREST}

The authors declare no conflict of interest.

\section{REFERENCES}

1. J. Arnt,T.Skarsfeldt, Do novel antipsychotics have similar pharmacological characteristics, A review of the evidence, Neuropsychopharmacology. 18 (1998) 63-101.

2. S. Sweetman., Matrindale. Editor, The Complete Drug Reference, Electronic Version, London, Pharmaceutical Press, 2006.

3. SM. Cheer, AJ. Wagstaff, A review of its use in the management of schizophrenia, CNS Drugs.18 (2004) 173-99.

4. F. Belal, A. Elbrashy, M. Eid, J. J. Nasr, Stabilityindicating HPLC method for the determination of quetiapine, Application to tablets and human plasma, J. Liq. Chromatogr.Relat. Technol. 31 (2008) 1283-1298.

5. PC. Davis, J. Wonga, O. Gefvertb, Analysis and pharmacokinetics of quetiapine and two metabolites in human plasma using reversed-phase HPLC with ultraviolet and electrochemical detection, J. Pharm. Biomed. Anal. 20 (1999) 271-282.

6. J. Sachse, J. Köller, S. Härtter, C. Hiemke, Automated analysis of quetiapine and other antipsychotic drugs in human blood by highperformance liquid chromatography with columnswitching and spectrophotometric detection, J. Chromatogr. B. 830 (2006) 342-348.

7. MA. Saracino, L. Mercolini, G. Flotta, LJ. Albers, R. Merli, MA. Raggi, Simultaneous determination of fluvoxamine isomers and quetiapine in human plasma by means of high-performanceliquidchro matography, J. Chromatogr. B, Analyt. Technol. Biomed. Life. Sci, 843 (2006) 227-233.

8. R. Mandrioli, S. Fanali, A. Ferranti, MA. Raggi, HPLC analysis of the novel antipsychotic drug quetiapine in human plasma, J. Pharm. Biomed. Anal. 30 (2002) 969-977.

9. C. Frahnert, ML. Rao, K. Grasmäder, Analysis of eighteen antidepressants, four atypical antipsychotics and active metabolites in serum by liquid chromatography, A simple tool for therapeutic drug monitoring, J. Chromatogr. B. 794 (2003) 35-47.

10. J. Hasselstroem, K. Linnet, Fully automated online quantification of quetiapine in human serum by solid phase extraction and liquid chromatography, 
J. Chromatogr. B, Analyt. Technol. Biomed. Life. Sci. 798 (2003) 9-16.

11. WB. Li, YZ. Xue, YM. Zhai, J. Zhang, GX. Guo, CY. Wang, Determination of quetiapine fumarate in serum by HPLC with ultraviolet detection,YaowuFenxiZazhi. 23 (2003) 247-251.

12. KY. Li, ZN. Cheng, X. Li, XL. Bai, BK. Zhang, F. Wang, Determination of quetiapine fumarate in serum by HPLC with ultraviolet detection, Acta. Pharmacol. Sin. 25 (2004) 110-114.

13. Nagaraju, Rajendraprasad, Kanakapura, Basavaiah, R. Urdigere, AnilKumar, Isocratic ultra-performance liquid chromatographic assay of quetiapine fumarate in pharmaceuticals, TJPS. 41 (1) (2017) 6-11.

14. JY. Tu, P. Xu, DH. Xu, HD. Li, Analysis of quetiapine and its two active metabolites, 7hydroxyquetiapine and 7-hydroxy-Ndealkylquetiapine, in rat plasma and cerebrospinal fluid, Chromatographia. 68 (2008) 525-532.

15. SA. Bella. Marino, AJ. Brown, XA. Conlan, NW. Barnett, Preliminaryevaluation of monolithic column high-performance liquid chromatography with tris (2,2'-bipyridyl) ruthenium (II) chemiluminescence detection for the determination of quetiapine in human body fluids, Talanta.77 (2009) 1873-1876.

16. MM. McMullin, Development of a gas chromatographic method for the determination of quetiapine in human serum, and a report of patient values, The Drug Monit 21 (1999) 459-469.

17. VN. Atanasov, KP. Kanev, MI. Mitewa, Detection and identification of atypical quetiapine metabolite in urine, Cent. Eur. J. Med. 3 (2008) 327-331.

18. SA. Ozkan, B. Dogan, B. Uslu, Voltammetric analysis of the novel atypical antipsychotic drug quetiapine in human serum and urine, Micro. chim. Acta. 153 (2006) 27-35.

19. S. Hillaert, L. Snoeck, W. Van den Bossche, Optimization and validation of a capillary zone electrophoretic method for the simultaneous analysis of four atypical antipsychotics, J. Chromatogr. 1033 (2004) 357-362.

20. V. Pucci, R. Mandrioli, A. Ferranti, S. Furlanetto, MA. Raggi, Quality control of commercial tablets containing the novel antipsychotic quetiapine, J. Pharm. Biomed. Anal. 32 (2003) 1037-1044.

21. B. Dhandapani, A. Somasundaram, SH. Raseed, M. Raja, K. Dhanabal, Development and validation of HPTLC method for estimation of quetiapine in bulk drug and in tablet dosage form, Int. J. Pharm. Tech. Res. 1 (2009) 139-141.

22. R. Skibiński, Ł. Komsta, I. Kosztyła, Comparative validation of quetiapine determination in tablets by NP-HPTLC and RP-HPTLC with densitometric and video densitometric detection, J. Planar. Chromatogr. Mod. TLC. 21 (2008) 289-294.

23. SR. Dhaneshwar, NG. Patre, MV. Mahadik, Stability-indicatingHPTLCmethodforquantitation of quetiapine fumarate in the pharmaceutical dosage form, Acta. Chromatographia. 21 (2009) 83-93.

24. RA. Fursule, DK. Rupala, MG. Khan, AA. Shirkhedkar, SJ. Surana, Determination of quetiapine fumarate and cilostazol in bulk and tablet by UV-spectrophotometry, Biosci. Bioethanol.Res.Asia.05,http://www.biotech-asia. org/display. asp?id= 429 (2008).

25. RX. Arulappa, M. Sundarapandian, S. Venkataraman, M. Boopathi, M. Kaurav, Spectrophotometric determination of quetiapine fumarate in bulk and dosageform, Res. J. Pharm. ech. 2 (2009) 884-885.

26. N. Rajendraprasad, K. Basavaiah, KB. Vinay, Extractive spectrophotometric determination of quetiapine fumarate in pharmaceuticals and spiked human urine, Croat. Chem. Acta. 85 (2012) 9-17.

27. N. Rajendraprasad, K. Basavaiah, KB. Vinay, Extractive spectrophotometric determination of quetiapine fumarate in pharmaceuticals and human urine using calmagite as an ion-pair reagent, Chem. Ind. Chem. Eng. Q. 17 (2011) 259-267.

28. KB. Vinay, HD. Revanasiddappa, PJ. Ramesh, N. Rajendraprasad, Titrimetric and sensitive spectrophotometric methods for the assay of quetiapine fumarate in pharmaceutical formulations, Chem. Ind. Chem. Eng. Q. 17 (2011) 99-106.

29. A. Cigdem, MC. Gokhan, LP. Murat, O. Feyyaz, Spectrophotometric methods for determination of quetiapine hemifumarate in pharmaceutical preparations using bromcresol purple and bromcresol green, Turk. J. Pharm. Sci. 9 (2012) 301-310.

30. W. Yuving, BM. Joel, JW. Brian, PK. Du, WM. Sarah, W. Bo, H. Rachel, MO. Samy, CR. Theodor, K. Rajesh, J. Bio. Chem. 35 (285) (2010) 25296-25307.

31. Vudagandla, Sreenivasulu, Dokku. RaghavaRao, BN. UmaMaheswari, Samar. K. Das, Abburi. Krishnaiah, JPBCS. 2 (4) (2011) 1. 
32. V. Kalyan. Chakravarthy, D . Gowri. Sankar, Rasayana. Chem. 5 (3) (2012) 293-310.

33. Ganji. Ramanaiah, D. Ramachandran, G. Srinivas, V. Srilakshmi, Purnachanda. Rao, Am. J. Pharm. Tech. Res. 2 (2) (2012).

34. K. Usmangani, Chhalotiya, K. Kashyap, Dimal. Bhatti, A. Shah, L. Sunil, Baldania. Jigar. R. Patel, Chemical Industry and Chemical Engineering Quarterly, 18 (1) (2012) 35-42.

35. MD. Parmar, KS. Nimavat, KB. Vyas, DVNS. Rao, R. Pande,International Journal for Pharmaceutical Research Scholars. 1 (3) (2012) 40-47.

36. S.A. Kamdar, V.M. Vaghela, P.A. Desai, International Journal of Chem Tech Research. 4 (3)(2012) 1193-1197.

37. S. Surani, R. Kimbahune, P. Kabra, G.H. Urmila, Der. Pharmacia. Lettre. 2 (5) (2010) 353-357.

38. Molleti. Srihari, Vinay. Rao, K.N. Jayaveera, Der. Pharma. Chemica. 5 (1) (2013) 81-89

39. R. Valarmathi, R. Senthamarai, S. Akilandeswari, S. Farisha. Banu, R. Saratha, V. Revathi, World
Journal Of Pharmacy And Pharmaceutical Sciences. 4 (4) (2016) 1083-1091.

40. N. Venugopal, A. Vijaya. Bhaskar. Reddy, G. Madhavi, Journal of Pharmaceutical and Biomedical Analysis. 90 (2014) 127-133.

41. A. Vijaya. Bhaskar. Reddy, Yusop. Zulkifli, Jaafar. Jafariah. Azmi, Aris. Juhaizah. Talib, Journal of Pharmaceutical and Biomedical Analysis. 128 (2016) 141-148.

42. A. Vijaya. Bhaskar. Reddy, N. Venugopal, V. Gangadhara. Reddy, G. Madhavi, Journal of Pharmaceutical and Biomedical Analysis. 84 (2013) 84-89.

43. International Conference on Harmonization of Technical Requirements for Registration of Pharmaceuticals for Human Use, ICH Harmonized Tripartite Guideline, Validation of Analytical Procedures, Text and Methodology Q2 (R1), London, Complementary Guideline on Methodology Dated 06 November 1996, Incorporated in November 2005. 